\title{
Influence of biomechanical and biochemical stimulation on the proliferation and differentiation of bone marrow stromal cells seeded on polyurethane scaffolds
}

\author{
SONGSONG TENG, CHAOXU LIU, DANIEL GUENTHER, MOHAMED OMAR, \\ CLAUDIA NEUNABER, CHRISTIAN KRETTEK and MICHAEL JAGODZINSKI \\ Department of Orthopedic Trauma, Hannover Medical School, 30625 Hannover, Germany
}

Received January 1, 2015; Accepted February 19, 2016

DOI: $10.3892 /$ etm.2016.3206

\begin{abstract}
The aim of the present investigation was to compare the effects of cyclic compression, perfusion, dexamethasone (DEX) and bone morphogenetic protein-7 (BMP-7) on the proliferation and differentiation of human bone marrow stromal cells (hBMSCs) in polyurethane scaffolds in a perfusion bioreactor. Polyurethane scaffolds seeded with hBMSCs were cultured under six different conditions, as follows: $10 \%$ Cyclic compression at 0.5 and $5 \mathrm{~Hz} ; 10 \mathrm{ml} / \mathrm{min}$ perfusion; $100 \mathrm{nM}$ DEX; $100 \mathrm{ng} / \mathrm{ml}$ BMP-7; and $1 \mathrm{ml} / \mathrm{min}$ perfusion without mechanical and biochemical stimulation (control). On days 7 and 14, samples were tested for the following data: Cell proliferation; mRNA expression of Runx2, COL1A1 and osteocalcin; osteocalcin content; calcium deposition; and the equilibrium modulus of the tissue specimen. The results indicated that BMP-7 and $10 \mathrm{ml} / \mathrm{min}$ perfusion promoted cell proliferation, which was inhibited by $5 \mathrm{~Hz}$ cyclic compression and DEX. On day 7, the $5 \mathrm{~Hz}$ cyclic compression inhibited Runx 2 expression, whereas the $0.5 \mathrm{~Hz}$ cyclic compression and BMP-7 upregulated the COL1A1 mRNA levels on day 7 and enhanced the osteocalcin expression on day 14. The DEX-treated hBMSCs exhibited downregulated osteocalcin expression. After 14 days, the BMP-7 group exhibited the highest calcium deposition, followed by the $0.5 \mathrm{~Hz}$ cyclic compression and the DEX groups. The equilibrium modulus of the engineered constructs significantly increased in the BMP-7, $0.5 \mathrm{~Hz}$ cyclic compression and DEX groups. In conclusion, the present results suggest that BMP-7 and perfusion enhance cell proliferation, whereas high frequency cyclic compression inhibits the proliferation and osteogenic differentiation of hBMSCs. Low frequency cyclic compression
\end{abstract}

Correspondence to: Dr Songsong Teng, Department of Orthopedic Trauma, Hannover Medical School, 1 Carl-Neuberg Street, 30625 Hannover, Germany

E-mail: songsongteng@gmail.com

Key words: biomechanical stimulation, biochemical stimulation, bone tissue engineering, polyurethane scaffold is more effective than DEX, but less effective compared with BMP-7 on the osteogenic differentiation of hBMSCs seeded on polyurethane scaffolds.

\section{Introduction}

In the last 20 years, the development of bone tissue engineering in three major components, namely osteogenic cells, scaffolds and stimulating factors, has made it a promising alternative for autologous bone grafting for bone repair and regeneration (1). Among the osteogenic cell types, the bone marrow stromal cells (BMSCs) are considered to be among the most promising cell sources for bone tissue engineering purposes (2). However, to direct BMSCs toward osteogenic lineage, essential regulatory signals, primarily including biochemical and/or biophysical stimuli, should be applied (3).

To the best of our knowledge, dexamethasone (DEX), a synthetic glucocorticoid, is the most widely used reagent to enhance the osteogenic differentiation of BMSCs (4). However, its potential side-effects, such as inhibition of cell proliferation and induction of osteoblast apoptosis, impede its further application for engineered bone constructs (5). Since the early 1990s, increasing numbers of investigators have realized the effects of mechanical stimulation on the behavior and function of BMSCs (6-8), and researchers have proposed the importance of mechanical forces in inducing BMSC differentiation and full maturation (9). Recently, it was reported that dynamic compressive loading was as effective as DEX at inducing matrix production during osteogenic differentiation of hBMSCs (5). Furthermore, fluid shear stress was more effective than DEX in the early osteogenic differentiation of BMSCs (10). In addition to DEX, bone morphogenetic proteins (BMPs) are also well-known as potent osteogenic stimulating factors that are able to promote the osteogenic differentiation of BMSCs and reduce their apoptosis (11). However, to date there have been no reports focusing on the influence of mechanical forces compared with that of BMPs on the proliferation and differentiation of BMSCs. BMP-2 and BMP-7 have been approved for clinical applications for bone repair (12). However, compared with BMP-2, BMP-7 is associated with a milder inflammatory response, particularly when used in high-dose treatments (13), and is capable of attenuating 
fibrosis (14), a common complication after orthopedic surgery. Thus, BMP-7 was employed in the present investigation.

In addition to various stimuli, a scaffold providing a three dimensional environment for cell growth and development is also crucial for bone tissue engineering $(15,16)$. Previously, the present authors reported that a 1,4-butanediisocyanate-based polyurethane (PU) scaffold could offer an ideal environment for the attachment and proliferation of human BMSCs (hBMSCs) in dynamic culture (17). This type of PU scaffold has been applied in patients for meniscus replacement for several years (18). Furthermore, a recent study also revealed promising outcomes of osteochondral repair using this scaffold (19). There may likewise be a clinical application potential for constructing tissue-engineered bone grafts using a patients' own BMSCs for bone defect repair (20).

In the present study, a PU scaffold consisting of a hard segment of 1,4-butane diisocyanate and butanediol, and a soft segment of poly( $\varepsilon$-caprolactone) was employed. Furthermore, a perfusion bioreactor system was used for optimizing the environment for rapid differentiation of hBMSCs. The objective of this study was to identify the effects of perfusion, cyclic compression, DEX and BMP-7 on the proliferation and differentiation of hBMSCs on the PU scaffolds in a dynamic culture system and to determine the most potent factor for enhancing the proliferation and osteogenic differentiation of hBMSCs.

\section{Materials and methods}

Harvest and cultivation of hBMSCs. All procedures were approved by the Institutional Ethical Committee of Hannover Medical School (Hannover, Germany). After written informed consent was obtained, bone marrow aspirates were collected from seven healthy human donors (four males and three females; mean age, $29 \pm 3.5$ years) who underwent exposure of their iliac crests during routine orthopedic procedures. Isolation and cultivation of hBMSCs was performed as per our previously described protocol (21). Briefly, the cells were purified by density gradient centrifugation at $1,200 \mathrm{x}$ g for $20 \mathrm{~min}$ at $4^{\circ} \mathrm{C}$ (Heraeus Labofuge 400R; Thermo Fisher Scientific, Inc., Waltham, MA, USA). Cells were then cultured in Dulbecco's modified Eagle's medium (DMEM)/Ham's F12 medium containing L-glutamine (Biochrom GmbH, Berlin, Germany) supplemented with $10 \%$ fetal calf serum (Gibco; Thermo Fisher Scientific, Inc.), $5 \mu \mathrm{g} / \mathrm{ml}$ ascorbic acid (Sigma-Aldrich, St. Louis, MO, USA), $3 \mathrm{ng} / \mathrm{ml}$ fibroblast growth factor-2 (FGF-2; PeproTech, Inc., Offenbach, Germany), $100 \mathrm{U} / \mathrm{ml}$ penicillin/streptomycin (Gibco) and $0.5 \mu \mathrm{g} / \mathrm{ml}$ amphotericin B (Biochrom $\mathrm{GmbH}$ ) at $37^{\circ} \mathrm{C}$ and $5 \% \mathrm{CO}_{2}$ in humidified atmosphere. After reaching confluence, cells were lysed with $0.05 \%$ trypsin (Gibco) and combined, and then the cell pool was subcultured. The hBMSCs from the third passage were used for the experiments.

PU scaffold preparation, cell seeding and culture. Biodegradable PU-based scaffolds (Actifit ${ }^{\circledR}$; Orteq Ltd., Groningen, The Netherlands) were fabricated according to the procedure described by van Tienen et al (22). Cylindrical scaffolds (diameter, $20 \mathrm{~mm}$; height, $5 \mathrm{~mm}$ ) with pore sizes ranging between 110 and $455 \mu \mathrm{m}$ (mean, $301 \mu \mathrm{m}$ ) and porosity of $\sim 80 \%$ were used (Fig. 1A and B). Prior to cell seeding, the scaffolds were immersed in culture medium without FGF-2 for 15 min with gentle shaking. After removing excess medium from the scaffolds, $10^{6} \mathrm{hBMSC}$ from the third passage were resuspended in $400 \mu$ l culture medium without FGF- 2 and seeded on each hydrated scaffold. After incubation at $37^{\circ} \mathrm{C}$ for $24 \mathrm{~h}$, the hBMSC-seeded PU scaffolds were cultured under six different conditions, including: Mechanical stimulation I group, 10\% cyclic compression at $0.5 \mathrm{~Hz}$ (perfusion rate, $1 \mathrm{ml} / \mathrm{min}$ ); mechanical stimulation II group, $10 \%$ cyclic compression at $5 \mathrm{~Hz}$ (perfusion rate, $1 \mathrm{ml} / \mathrm{min}$; ); perfusion group, $10 \mathrm{ml} / \mathrm{min}$ continuous perfusion; DEX group, 100 nM DEX (Merck KGaA, Darmstadt, Germany; perfusion rate, $1 \mathrm{ml} / \mathrm{min}$ ); BMP-7 group, 100 ng/ml BMP-7 (Stryker Biotech, Hopkinton, MA, USA; perfusion rate, $1 \mathrm{ml} / \mathrm{min}$ ); and the control group, $1 \mathrm{ml} / \mathrm{min}$ continuous perfusion in a custom-made perfusion bioreactor (23) maintained at $37^{\circ} \mathrm{C}$ in $5 \% \mathrm{CO}_{2}$ in an incubator. The volume of the culture medium without FGF-2 in each bioreactor was $150 \mathrm{ml}$, and half of the medium volume was changed every three days. On days 7 and 14, the scaffolds were harvested, and each scaffold was split into six equal parts for the following six analyses.

MTS assay for cell proliferation. On days 7 and 14, the cell-loaded scaffolds were cut into $1-\mathrm{mm}^{3}$ pieces for the cell proliferation assay. Then, 2 ml MTS solution (1:20; Promega Corporation, Madison, WI, USA) was added to the small pieces. After $2 \mathrm{~h}$ of incubation at $37^{\circ} \mathrm{C}$, the reaction was stopped using 10\% sodium dodecyl sulfate (Sigma-Aldrich). The solution was removed, and the absorbance was read at $490 \mathrm{~nm}$ using an absorbance reader (BioTek Instruments, Inc., Winooski, VT, USA). The cell number was determined using the calibration data ( ix points, $n=3, R^{2}=0.99$ ) obtained using cells from the same culture (23).

mRNA expression analysis. On days 7 and 14, total cellular RNA was extracted from the cell-scaffold constructs using the NucleoSpin ${ }^{\circledR}$ RNA II kit (Macherey-Nagel GmbH \& Co. KG, Düren, Germany). Genomic DNA was removed using DNase supplied with the kit. Total mRNA was reverse transcribed into cDNA using the High-Capacity cDNA Reverse Transcriptase Kit (Applied Biosystems; Thermo Fisher Scientific, Inc., Waltham, MA, USA). Quantitative real-time polymerase chain reaction (qPCR) was performed to measure transcript levels of three osteogenic marker genes, namely Runx2 (Hs00231692_m1), COL1A1 (Hs00164004_m1) and osteocalcin (Hs01587814_g1) and GAPDH (Hs02758991_g1) ,using a StepOnePlus qPCR system (4376600; Thermo Fisher Scientific, Inc.). Commercially available TaqMan primer/probes (4331182) and TaqMan Expression Master mix (4369016; Applied Biosystems). The reaction mixture contained $2 \mu \mathrm{l}$ (100 ng) cDNA, $1 \mu \mathrm{l}$ primer, $10 \mu \mathrm{l}$ Master mix and $7 \mu \mathrm{l}$ nuclease-free water. qPCR cycling conditions were as follows: $50^{\circ} \mathrm{C}$ for $2 \mathrm{~min}, 95^{\circ} \mathrm{C}$ for $10 \mathrm{~min}, 40$ cycles of $95^{\circ} \mathrm{C}$ for $15 \mathrm{sec}$ and $60^{\circ} \mathrm{C}$ for $1 \mathrm{~min}$. Negative (nuclease-free water) and reverse transcriptase controls were used. Three technical replicates were performed, and experiments were repeated independently three times. The $\mathrm{Cq}$ values of targeted genes were normalized against that of the housekeeping gene GAPDH (Hs02758991_g1). Data were expressed relative to control using the $2^{-\Delta \Delta \mathrm{Cq}}$ formula (24). 

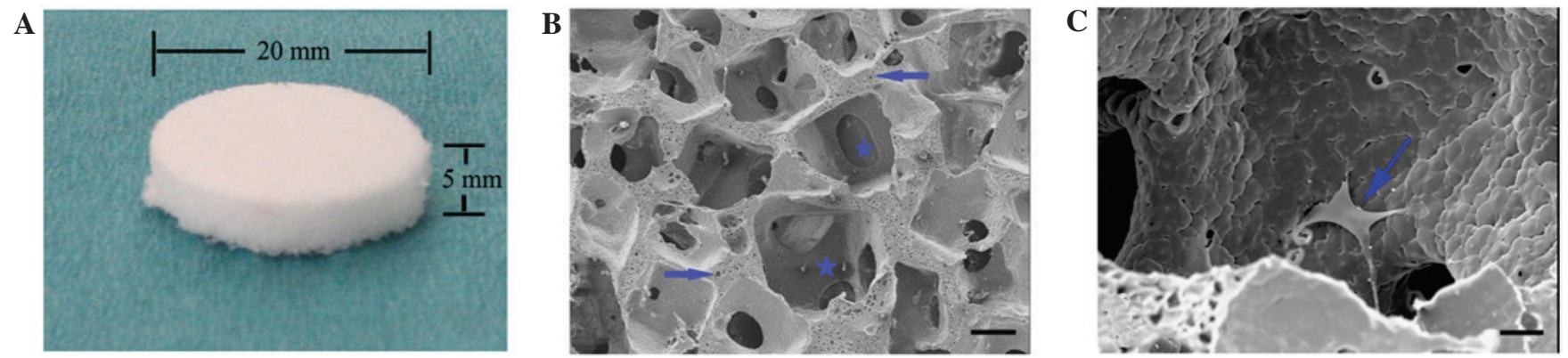

Figure 1. (A) Porous polyurethane scaffold with 20-mm diameter and 5-mm thickness. (B) Scanning electron microscope (SEM) photograph of the polyurethane scaffold (scale bar, $100 \mu \mathrm{m}$ ). Star: macro pore; Arrow: micro pore. (C) SEM photograph of the human bone marrow stromal cell (hBMSC)-loaded scaffold $24 \mathrm{~h}$ after seeding (scale bar, $20 \mu \mathrm{m}$ ). Arrow: hBMSCs.

ELISA analysis of osteocalcin. On days 7 and 14, hBMSCs in the scaffolds were lysed in $1 \mathrm{ml}$ RIPA buffer (Thermo Fisher Scientific, Inc.) overnight at $4^{\circ} \mathrm{C}$. After centrifugation at $12,000 \times \mathrm{g}$ for $10 \mathrm{~min}$, the supernatant was gathered and the osteocalcin levels were determined using an N-MID ${ }^{\circledR}$ Osteocalcin ELISA kit (Immunodiagnostic Systems Holdings PLC, The Boldons, UK) according to the manufacturer's instructions. The amount of total protein was quantified using Coomassie Plus Assay Reagent (Thermo Fisher Scientific, Inc.). The osteocalcin content was normalized against that of total protein.

Histological analysis. After collection from the bioreactor on days 7 and 14, the scaffolds were fixed in $4 \%$ formaldehyde (Otto Fischar GmbH \& Co. KG, Saarbrücken, Germany) and then embedded in the $\mathrm{OCT}^{\mathrm{TM}}$ compound (Sakura Finetek Europe B.V., Alphen, The Netherlands). Next, 30- $\mu \mathrm{m}$ thick sections were processed at $-20^{\circ} \mathrm{C}$ with a freezing microtome (Microm International Gmbh, Walldorf, Germany) for histological analysis. Nuclear fast red (Sigma-Aldrich) and Alizarin Red S (Merck KGaA) staining was performed to observe the distribution of hBMSCs and calcium deposition in the scaffolds, respectively. Quantitative analyses of the mineralization from the Alizarin Red S staining images were performed using Image-Pro Plus software, version 6.0 (Media Cybernetics, Inc., Rockville, MD, USA) (25).

Scanning electron microscopy (SEM). On days 7 and 14, the scaffolds were collected and fixed with $2.5 \%$ glutaraldehyde (Agar Scientific, Ltd., Stansted, UK) in $0.1 \mathrm{M}$ cacodylate buffer ( $\mathrm{pH}$ 7.4; Merck KGaA) for $24 \mathrm{~h}$. After rinsing in buffer, the scaffolds were dehydrated with graded ethanol changes $(25,50,75,90$ and $100 \%)$. Then, the specimens were dried using the liquid carbon dioxide to replace the ethanol within the scaffolds for 10 cycles ( 5 min per cycle), coated with $\mathrm{Au}$ (Quorom Technologies, Ltd., Laughton, UK) and observed with SEM. In addition, at $24 \mathrm{~h}$ after seeding, the cell-seeded scaffolds were observed using the same procedure.

Biomechanical evaluation. Disks of 1-mm thickness and $6-\mathrm{mm}$ diameter were cut from the central region of the hBMSC-seeded scaffolds from days 7 and 14 and mounted in a cylindrical confining chamber (Zwick/Roell 1445; Zwick GmbH \& Co. KG, Ulm, Germany) (17). Each sample was compressed by a plunger above the chamber using

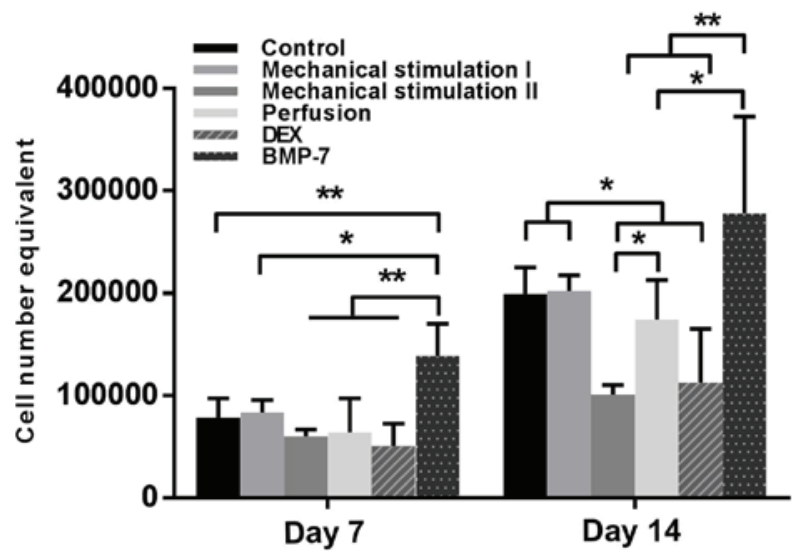

Figure 2. MTS assay for the proliferation of human bone marrow stromal cells (hBMSCs) on the polyurethane scaffolds cultured under different conditions on days 7 and 14 . ${ }^{*} \mathrm{P}<0.05,{ }^{* *} \mathrm{P}<0.01, \mathrm{n}=3$. Dex, dexamethasone; BMP-7, bone morphogenetic protein-7.

10 subsequent displacements with $5 \%$ strain, up to a $50 \%$ total strain. Based on the force recorded after each displacement, a stress-strain curve was generated. The equilibrium modulus of each sample was determined by the slope of the stress-strain curve (26). Furthermore, the equilibrium modulus of the empty scaffold was measured using the same procedure.

Statistical analysis. All experiments were performed in triplicate. Data are expressed as the mean \pm standard deviation. Comparisons among groups were performed using one-way analysis of variance, with the Student-Newman-Keuls test. SPSS software, version 15.0 (SPSS, Inc., Chicago, IL, USA) was used to conduct all statistical tests. $\mathrm{P}<0.05$ was considered to indicate a statistically significant difference.

\section{Results}

MTS assay for cell proliferation and nuclear fast red staining. Cell number in all of the groups increased over time, and no significant difference was observed between controls and the mechanical stimulation I groups at any time point. On day 7 , the BMP-7 group had the highest cell number $(\mathrm{P}<0.01)$, and compared with that of the mechanical stimulation I, the effect of mechanical stimulation II resulted in lower cell proliferation; however, there was no significant difference. On day 14, 
A
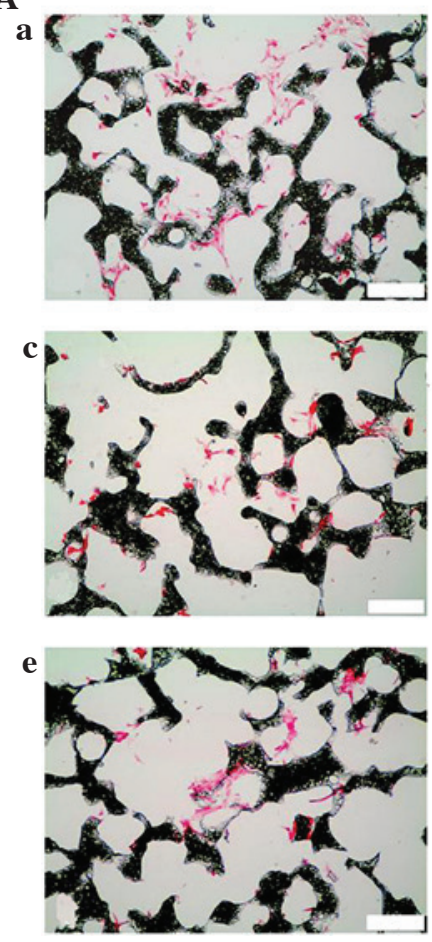
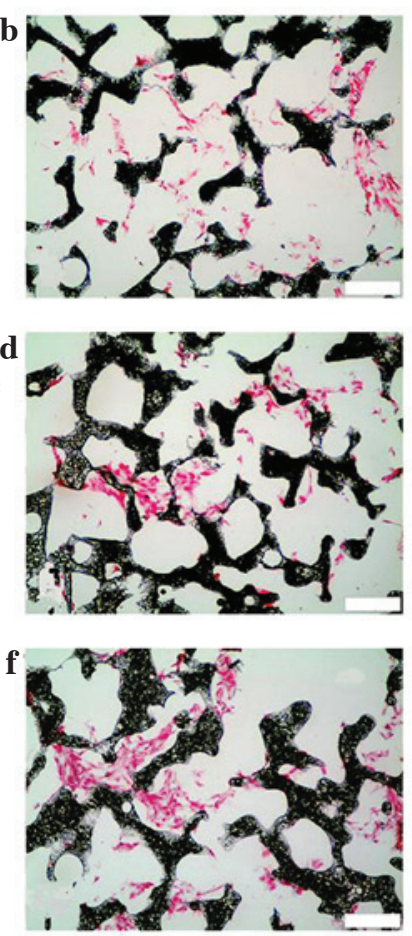

B
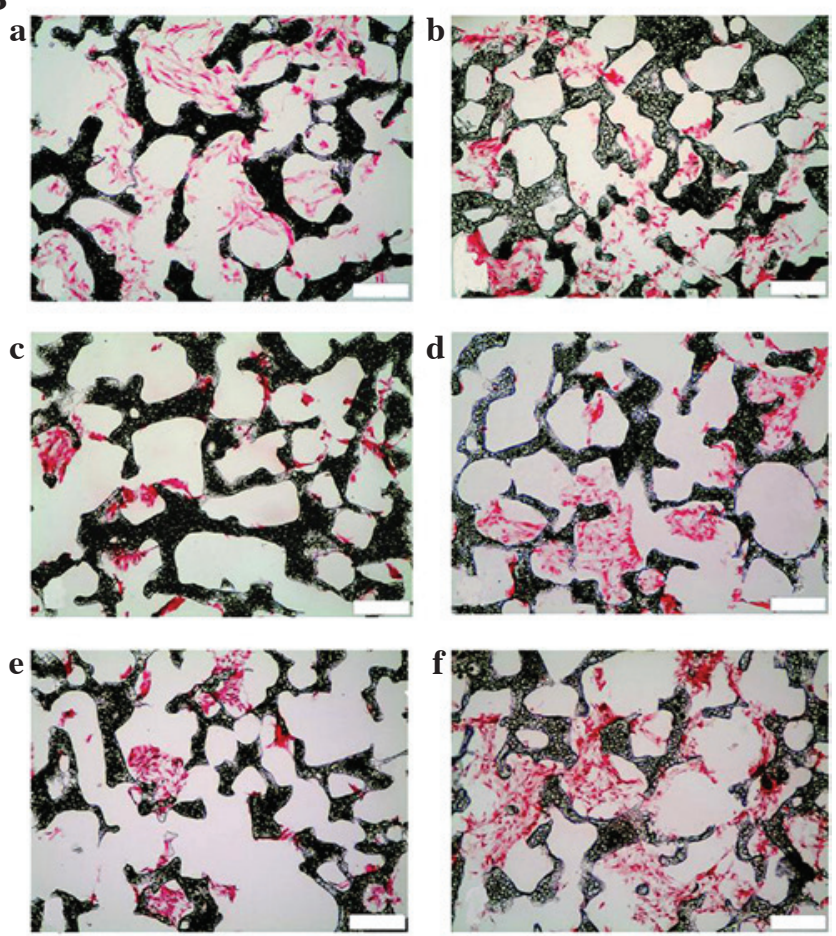

Figure 3. Nuclear fast red staining of human bone marrow stromal cell-seeded scaffolds cultured under different conditions on (A) day 7 and (B) day 14 (scale bar, $100 \mu \mathrm{m}$ ). a, Control; b, Mechanical stimulation I group; c, Mechanical stimulation II group; d, Perfusion group; e, DEX group; f, BMP-7 group. DEX, dexamethasone; BMP-7, bone morphogenetic protein-7.

the mechanical stimulation II and DEX groups had lower cell numbers $(\mathrm{P}<0.05)$, which was in contrast with the control, the mechanical stimulation I and BMP-7 groups. Furthermore, the maximum cell number was observed in the BMP-7 group, which was significantly increased compared with the mechanical stimulation II $(\mathrm{P}<0.01)$, DEX $(\mathrm{P}<0.01)$ and perfusion $(\mathrm{P}<0.05)$ groups (Fig. 2).

Sections were stained with nuclear fast red to determine the distribution of the hBMSCs within the scaffolds. The cell number increased over time in all groups, and the BMP-7 group always presented the largest number. In contrast, after 14 days, relatively few cells were observed in the mechanical stimulation II group. Although the number of BMSCs was low in the scaffolds of the perfusion group during the first seven days, a high density of cells was observed in a few parts of the scaffolds after 14 days (Fig. 3).

SEM analysis. At $24 \mathrm{~h}$ after seeding, the attached rounded cells became polygonal in shape (Fig. 1C). After seven days, the cells extended pseudopodia and spread uniformly on the porous walls of the scaffolds in the control, mechanical stimulation I, perfusion and BMP-7 groups, and there were noticeably more cells in the BMP-7 groups compared with the other five groups, which was consistent with the outcome of the MTS assay. After 14 days, the BMP-7 group continued to exhibit the highest cell density and quantity of extracellular matrix (ECM), followed by the mechanical stimulation I group. High cell density was observed in a few parts of the scaffolds in the perfusion group. However, the cell density in the mechanical stimulation II and DEX groups was always lower compared with the other groups (Fig. 4).
Gene expression analysis. On day 7, compared with the control, the Runx2 mRNA level in the mechanical stimulation II group was significantly decreased $(\mathrm{P}<0.05)$, and the COL1A1 mRNA levels of the mechanical stimulation I, mechanical stimulation II and BMP-7 groups were significantly increased $(\mathrm{P}<0.05)$. However, the DEX group exhibited significantly reduced osteocalcin mRNA levels $(\mathrm{P}<0.01)$ at this time point. On day 14, the maximum and minimum osteocalcin mRNA levels were observed in the BMP-7 $(\mathrm{P}<0.05)$ and DEX groups $(\mathrm{P}<0.01)$, respectively. There was an upregulation of osteocalcin expression in the mechanical stimulation I group $(\mathrm{P}<0.05)$, which also exhibited markedly increased osteocalcin expression compared with the mechanical stimulation II group $(\mathrm{P}<0.01)$. In addition, the BMP-7 group had a higher osteocalcin mRNA levels compared with the mechanical stimulation I group $(\mathrm{P}<0.05)$. No significant difference was detected in the mRNA levels of Runx 2 and COL1A1 among the six groups at this time point; however, there was an overall upward trend during the 14 days of dynamic culture (Fig. 5A).

Osteocalcin evaluation. During the first seven days, there was no significant difference among the six groups in osteocalcin levels. On day 14, the osteocalcin levels in the mechanical stimulation I and the BMP-7 groups were significantly higher than in the control $(\mathrm{P}<0.05)$. However, although the average level of osteocalcin in the BMP-7 group was higher compared with the mechanical stimulation I group, no significant difference was observed. By contrast, stimulation with DEX resulted in decreased osteocalcin levels $(\mathrm{P}<0.05)$ (Fig. 5B). 
A
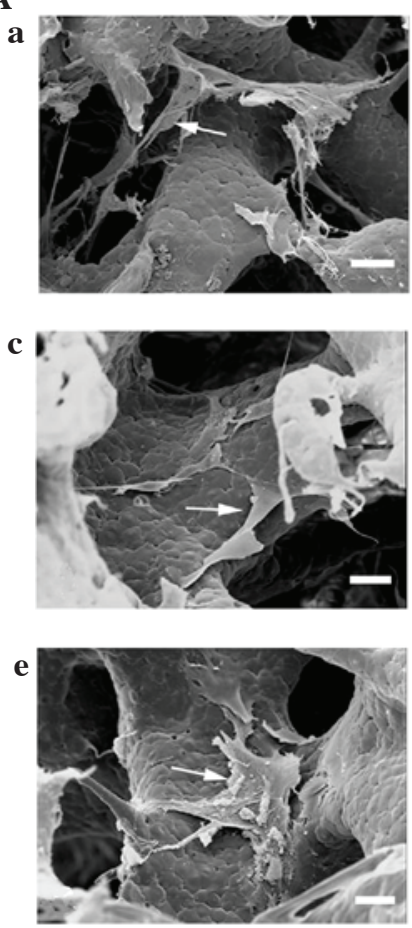
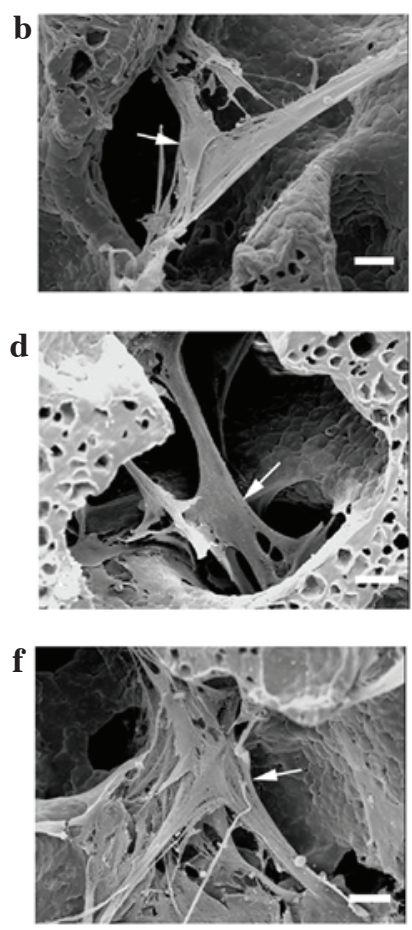

B
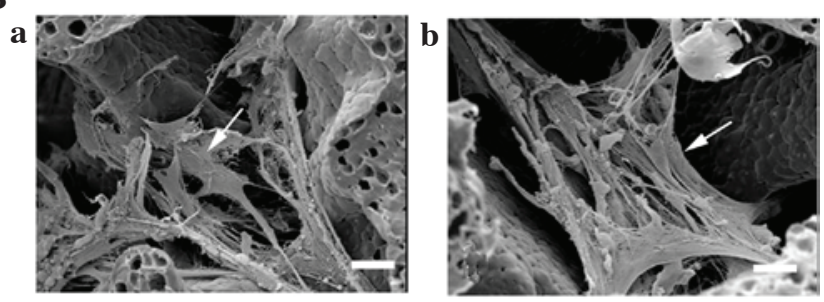

c
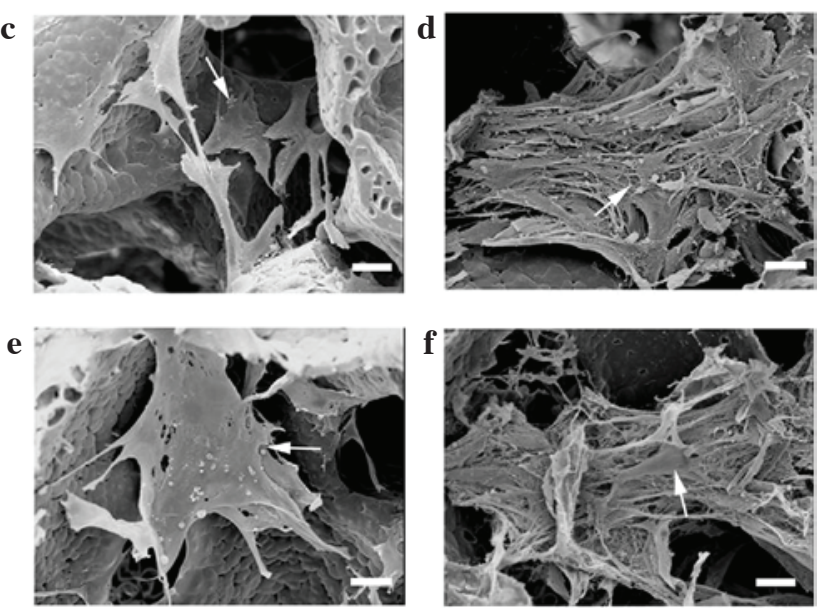

Figure 4. Scanning electron microscopy images of human bone marrow stromal cells (hBMSCs) on the scaffolds cultured under different conditions on (A) day 7 and (B) day 14 (scale bar, $20 \mu \mathrm{m}$ ). Arrow: hBMSCs. a, Control; b, Mechanical stimulation I group; c, Mechanical stimulation II group; d, Perfusion group; e, DEX group; f, BMP-7 group. DEX, dexamethasone; BMP-7, bone morphogenetic protein-7.
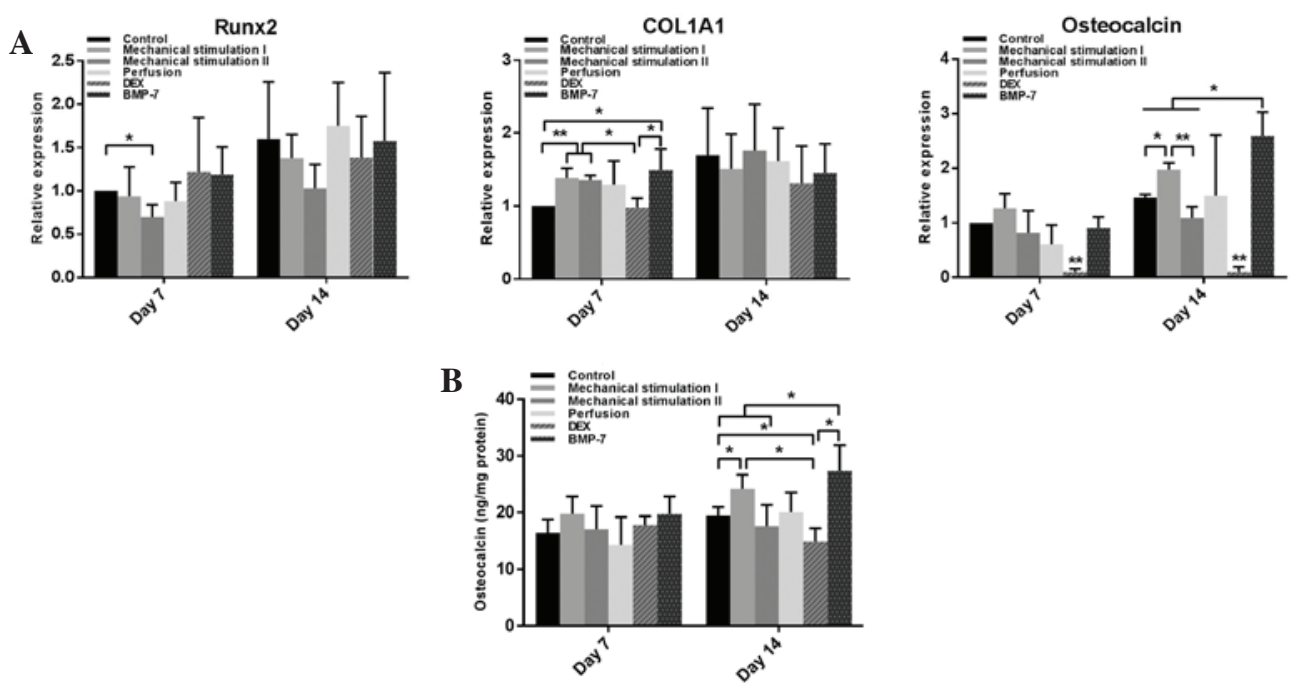

Figure 5. (A) mRNA expression of Runx2, COL1A1 and osteocalcin on days 7 and 14 . Data are expressed as $x$-fold $\left(2^{-\Delta \Delta C q}\right)$ vs. mRNA of control on day 7 . ${ }^{*} \mathrm{P}<0.05,{ }^{* *} \mathrm{P}<0.01, \mathrm{n}=3$. (B) ELISA assay for osteocalcin/protein estimated within the scaffolds on days 7 and 14 . ${ }^{*} \mathrm{P}<0.05, \mathrm{n}=3$. DEX, dexamethasone; BMP-7, bone morphogenetic protein-7.

Alizarin Red S staining. Since day 7, calcium deposition was observed in the mechanical stimulation I and BMP-7 groups. After 14 days, the BMP-7 group displayed the most marked staining, followed by the mechanical stimulation I and DEX groups. Less intense staining was exhibited in the perfusion group. No apparent calcium deposition was detected in the mechanical stimulation II group at either time point (Fig. 6). According to the quantitative analyses, the mechanical stimulation I and BMP-7 groups had significantly higher calcium deposition compared with the other groups $(\mathrm{P}<0.01)$ at each time point. After 14 days, compared with control, there was significantly increased calcium deposition in the DEX $(\mathrm{P}<0.01)$ and perfusion $(\mathrm{P}<0.05)$ groups (Fig. 7).

Equilibrium modulus. On day 7, no significant difference in the equilibrium modulus was identified between the empty scaffold and each of the cell-seeded scaffolds. After 14 days, a significantly higher equilibrium modulus was observed in the mechanical stimulation I, DEX and BMP-7 groups $(\mathrm{P}<0.05)$, compared with that of empty scaffolds (Fig. 8). 
A
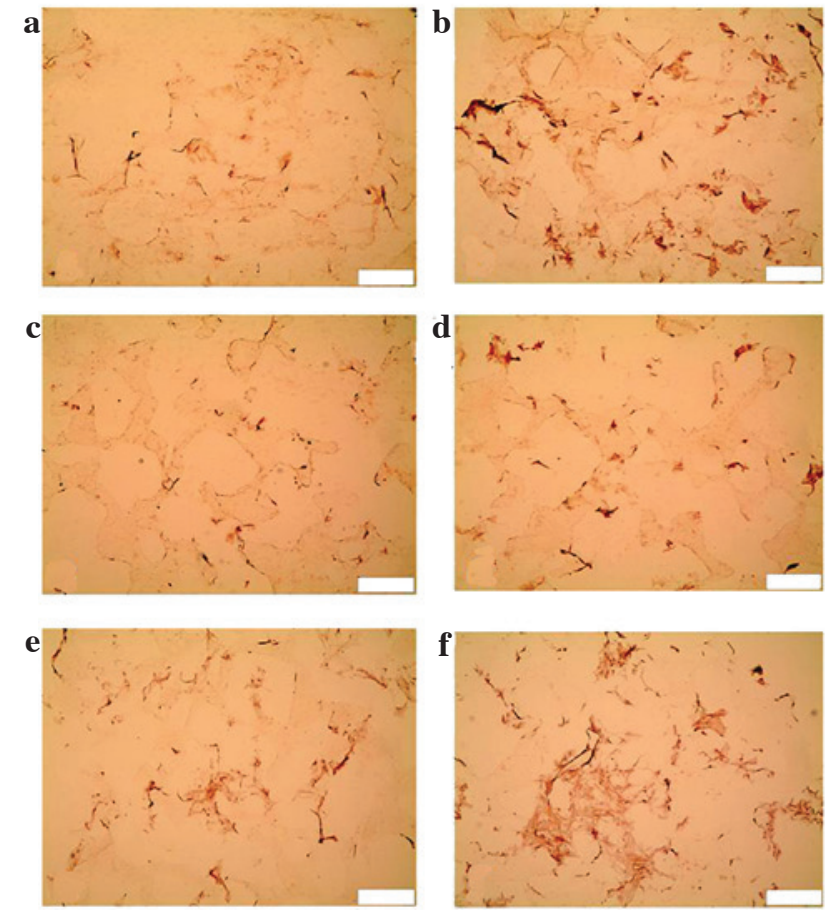

B
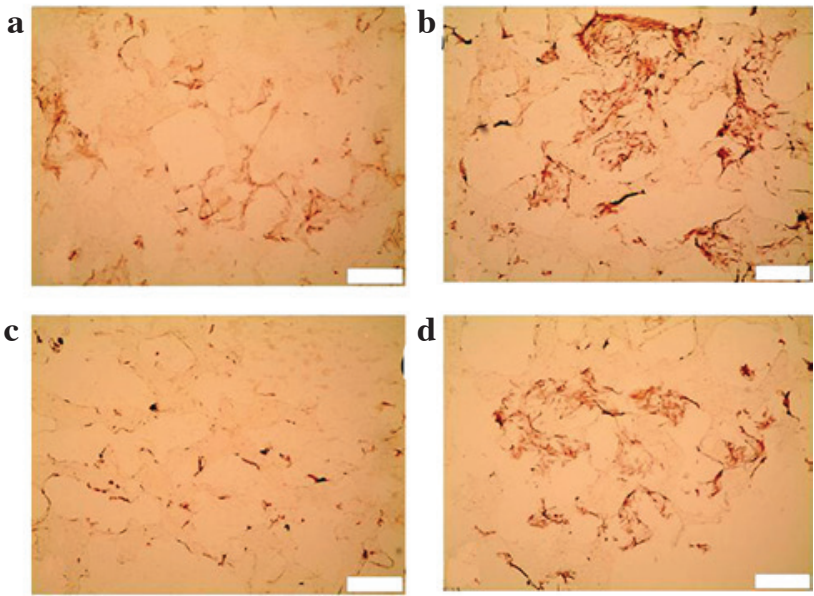

e

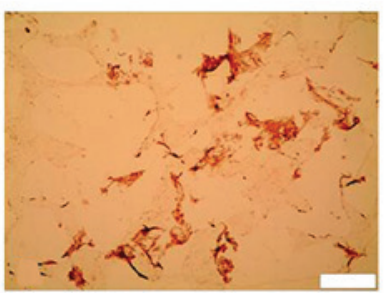

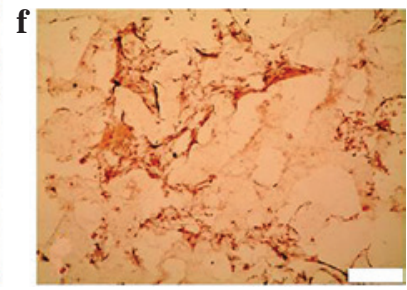

Figure 6. Alizarin Red S staining of human bone marrow stromal cell-seeded scaffolds cultured under different conditions on (A) day 7 and (B) day 14 (scale bar, $100 \mu \mathrm{m}$ ). a, Control; b, Mechanical stimulation I group; c, Mechanical stimulation II group; d, Perfusion group; e, DEX group; f, BMP-7 group. DEX, dexamethasone; BMP-7, bone morphogenetic protein-7.

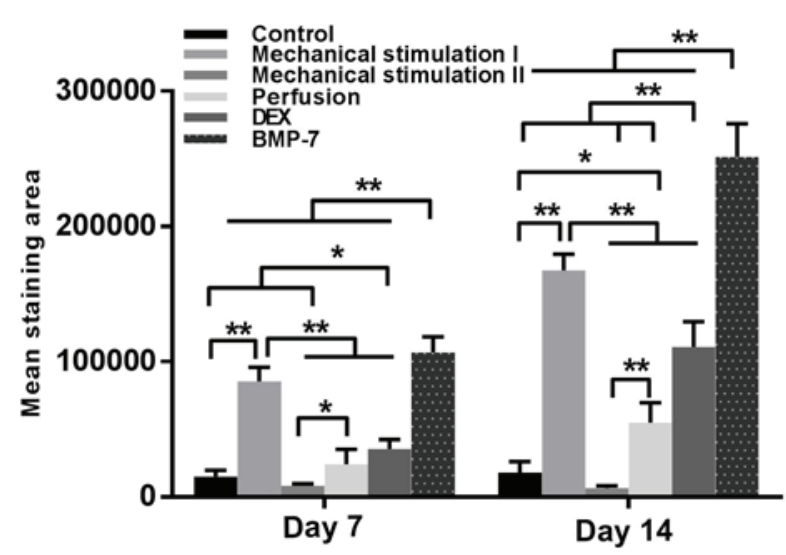

Figure 7. Quantitative analyses of the mineralization from the Alizarin Red $S$ staining images. ${ }^{*} \mathrm{P}<0.05,{ }^{* *} \mathrm{P}<0.01$. DEX, dexamethasone; BMP-7, bone morphogenetic protein-7.

\section{Discussion}

Osteoprogenitor cells at the fracture sites experience local physical stimuli, such as fluid shear stress or cyclic axial compression (27). It has been reported that mechanical loading plays an important role in inducing osteoprogenitor cells in the bone marrow stroma to differentiate towards osteoblasts at the cortical bone surface in vivo (28). Based on these results, various studies have been performed to identify the optimum mechanical stimuli to enhance the osteogenic differentiation of MSCs, to replace pharmaceutical agents with potential side effects $(5,21,29)$. As mentioned above, appropriate mechanical forces may be as effective or more so than DEX, a main component in the osteogenic medium (5). In addition to DEX,

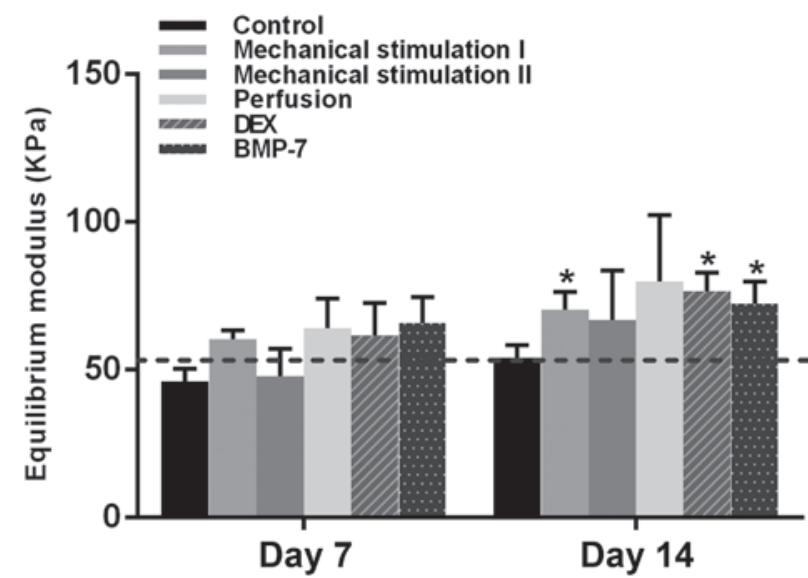

Figure 8. Equilibrium modulus of human bone marrow stromal cell-seeded scaffolds cultured under different conditions on days 7 and 14 compared with empty scaffolds (baseline). ${ }^{*} \mathrm{P}<0.05, \mathrm{n}=3$. DEX, dexamethasone; BMP-7, bone morphogenetic protein-7.

certain protein-based growth factors, such as BMPs, are well-known as potent osteoinductive growth factors. However, their intrinsic drawbacks, such as short half-life, neoplastic risk, osteoclastic activation, immunosuppressive properties and high cost (30), necessitate the comparison of the osteoinductive abilities between mechanical loading and BMPs.

It has been demonstrated that different strain rates and frequencies may lead to different results (31). Sittichokechaiwut et al (5) determined the effectiveness of 5\% compressive strain at $1 \mathrm{~Hz}$ on the enhancement of hBMSC osteodifferentiation. Michalopoulos et al (32) reported that hBMSCs differentiate to an osteogenic lineage under $10 \%$ 
cyclic compressive strain and to an osteochondrogenic lineage under $15 \%$ cyclic compressive strain at $1 \mathrm{~Hz}$. The present group previously demonstrated that $10 \%$ cyclic compression at $0.5 \mathrm{~Hz}$ was effective for the osteodifferentiation of hBMSCs (23). To date, little is known about the influence of strain frequencies on the behavior of cells. Additionally, fluid flow has been considered to induce or enhance osteogenesis in MSCs (33). Therefore, the common mechanical $(10 \%$ cyclic compression of low and high frequencies; $10 \mathrm{ml} / \mathrm{min}$ continuous perfusion) and biochemical stimulation (DEX; BMP-7) were included in the present study and compared their influence on the proliferation and differentiation of hBMSCs in a perfusion bioreactor.

To date, scaffolds with pore sizes ranging between 20 and $1,500 \mu \mathrm{m}$ have been utilized in bone tissue engineering; numerous investigators have suggested that the mean pore size should be $>300 \mu \mathrm{m}$ for optimal bone regeneration and vascularization within the constructs (34-37). The mean pore size of the PU scaffolds in the present investigation were consistent with the mainstream perspective. In a previous study by the present authors, 1,4-butane diisocyanate-based polyurethane scaffolds were found to be non-cytotoxic and could provide an ideal environment for $\mathrm{hBMSC}$ adhesion and proliferation (17). This result was reconfirmed in the present study, as the MTS assay demonstrated a continuing increase in the cell number of all groups without showing any obvious adverse effects on cell proliferation. Furthermore, as an elastomeric cancellous bone graft substitute, PU scaffolds are superior to scaffolds made of rigid polymers, can have intimate contact with the recipients' bone ends, obviating shear forces at the bone-implant interface and possess excellent resistance to plastic deformation and elastic recovery under load (38). Therefore, the PU scaffolds are speculated to be a promising bone substitute for autologous bone grafts, particularly in large-scale bone defect reconstruction.

To the best of our knowledge, perfusion is an effective factor for promoting hBMSC proliferation $(23,39)$. However, from the MTS assay, no significant difference was observed between the control and perfusion groups. Unexpectedly, according to the results of the nuclear fast red staining and the SEM assay, high cell density was observed in certain areas of the scaffolds in the perfusion group. It seems that high perfusion rate may detach the cells from the scaffolds at the beginning (17). Afterwards, the proliferation of the remaining cells was enhanced under continuous perfusion, which may improve the transportation of nutrients, such as fetal calf serum (9). Consistent with the outcomes of the study by Shea et al (40), BMP-7 promoted cell proliferation according to the present results. By contrast, DEX markedly inhibited hBMSC proliferation, a side effect also reported by other groups (41). Pelaez et al (42) demonstrated that cyclic compression maintained the viability of hBMSCs. In the present study, cyclic compression of low frequency did not affect the proliferation of hBMSCs, whereas high frequency cyclic compression had a negative effect, which indicates that even short period high frequency mechanical stimulation is able to mitigate cell proliferation. According to the SEM images, the cells spread on the porous walls and proliferated well, indicating that favorable circumstance for cell attachment and proliferation can be supplied by this type of PU scaffold. Consistent with the outcome of the MTS assay, the BMP-7 group always exhibited the highest cell density in the scaffolds. Furthermore, substantial quantities of ECM around the cells was observed in the BMP-7 and mechanical stimulation I groups. Clustering of cells and synthesis of ECM are considered as indicators of osteogenic differentiation (43).

It is well known that the expression of genes Runx2, COL1A1 and osteocalcin are crucially involved in the osteogenic commitment of MSCs (44). Following the downregulation of Runx2, high frequency cyclic compression appeared to inhibit osteogenic differentiation of hBMSCs. There was no significant difference in Runx 2 observed among other groups; however, there was an overall upward trend. Similar results were observed in the study of Frank et al (45), which showed that Runx2 mRNA levels in hBMSCs were slightly elevated during osteogenic differentiation. It has been proposed that the formation of type I collagen is a crucial part of the osteogenic differentiation process, as it can interact with integrins, major cell receptors for collagen, which is required for the induction of bone-related gene expression (46). The results of the present study suggest that the expression of COL1A1 mRNA is sensitive to mechanical stimulation irrespective of the frequencies of the stimuli, and mechanical stimulation is as effective as BMP-7 in the enhancement of COL1A1 expression. As a late-stage marker of osteoblast maturation, low frequency cyclic compression and BMP-7 resulted in the upregulation of osteocalcin expression at the mRNA and protein levels, indicating that the hBMSCs differentiated into preosteoblastic phenotype during the 14 days of dynamic culture, and that mechanical stimulation is able to promote the osteogenic differentiation of hBMSCS in the absence of biochemical cues. However, the addition of DEX resulted in reduced expression of osteocalcin. Similarly, Fiorentini et al (47) demonstrated that DEX enhanced the ALP expression and mineralization of hBMSCs, but caused substantially declined osteocalcin mRNA levels, which reconfirmed the views of Ito et al (48) that glucocorticoids failed to induce terminal osteoblast differentiation.

In the present study, the highest calcium deposition was observed in the BMP-7-stimulated hBMSCs, and no mineralization occurred in the high frequency mechanical stimulation group. Although the stimulation of DEX and ascorbic acid resulted in the downregulation of osteocalcin, a certain degree of calcium deposition was observed, which was significantly lower compared with the low frequency mechanically stimulated hBMSCs. This implies that the mineralization of hBMSCs can be enhanced without the presence of biochemical cues. Accumulation of ECM, particularly calcium, led to the increased equilibrium modulus of the cell-seeded scaffolds, the importance of which has been well illustrated (49). Previous studies reported the positive impact of continuous perfusion on cell mineralization $(50,51)$. However, in the present study, a small degree of calcium deposition was observed in the perfusion group, less than that in the mechanical stimulation I group. According to our previous results (23), continuous perfusion is the primary stimulus for hBMSC proliferation, whereas mechanical stimulation promotes the osteogenic differentiation of hBMSCs. Duty et al (52) demonstrated that in vivo cyclic compression loading enhanced the mineralization in the MSC-seeded constructs, which suggests that the design of 
engineered constructs for bone repair should premeditate the interplays with the local mechanical circumstance.

In conclusion, BMP-7 and perfusion are able to enhance cell proliferation, and high frequency compression resulted in decreased proliferation and inhibited osteogenic differentiation. Low frequency cyclic compression is more effective than DEX, but less effective than BMP-7 on the osteogenic differentiation of hBMSCs seeded on a polyurethane scaffold. In the future, further in vivo studies are required to validate the safety and functionality of bone substitutes engineered from different cell lines, following biomechanical or biochemical stimulation.

\section{Acknowledgements}

This study was supported by the German Research Foundation (Deutsche Forschungsgemeinschaft; DFG Grant JA 1086/3-1). The authors thank Roland Meister for technical assistance.

\section{References}

1. Murphy CM, O'Brien FJ, Little DG and Schindeler A: Cell-scaffold interactions in the bone tissue engineering triad. Eur Cell Mater 26: 120-132, 2013.

2. Colnot C: Cell sources for bone tissue engineering: Insights from basic science. Tissue Eng Part B Rev 17: 449-457, 2011.

3. Wang YK and Chen CS: Cell adhesion and mechanical stimulation in the regulation of mesenchymal stem cell differentiation. J Cell Mol Med 17: 823-832, 2013.

4. Langenbach F and Handschel J: Effects of dexamethasone, ascorbic acid and beta-glycerophosphate on the osteogenic differentiation of stem cells in vitro. Stem Cell Res Ther 4: 117 2013.

5. Sittichokechaiwut A, Edwards JH, Scutt AM and Reilly GC: Short bouts of mechanical loading are as effective as dexamethasone at inducing matrix production by human bone marrow mesenchymal stem cell. Eur Cell Mater 20: 45-57, 2010

6. Li R, Liang L, Dou Y, Huang Z, Mo H, Wang Y and Yu B: Mechanical strain regulates osteogenic and adipogenic differentiation of bone marrow mesenchymal stem cells. Biomed Res Int 2015: 873251, 2015.

7. Cardwell RD, Kluge JA, Thayer PS, Guelcher SA, Dahlgren LA Kaplan DL and Goldstein AS: Static and cyclic mechanical loading of mesenchymal stem cells on elastomeric, electrospun polyurethane meshes. J Biomech Eng 137: 2015.

8. Kim TJ, Joo C, Seong J, Vafabakhsh R, Botvinick EL, Berns MW, Palmer AE, Wang N, Ha T, Jakobsson E et al: Distinct mechanisms regulating mechanical force-induced $\mathrm{Ca}^{2+}$ signals at the plasma membrane and the ER in human MSCs. eLife 4: e04876, 2015.

9. Delaine-Smith RM, MacNeil S and Reilly GC: Matrix production and collagen structure are enhanced in two types of osteogenic progenitor cells by a simple fluid shear stress stimulus. Eur Cell Mater 24: 162-174, 2012.

10. Yourek G, McCormick SM, Mao JJ and Reilly GC: Shear stress induces osteogenic differentiation of human mesenchymal stem cells. Regen Med 5: 713-724, 2010.

11. Liu Y, Wu J, Zhu Y and Han J: Therapeutic application of mesenchymal stem cells in bone and joint diseases. Clin Exp Med 14. $13-24,2014$.

12. Gautschi OP, Frey SP and Zellweger R: Bone morphogenetic proteins in clinical applications. ANZ J Surg 77: 626-631, 2007.

13. Lee KB, Taghavi CE, Murray SS, Song KJ, Keorochana G and Wang JC: BMP induced inflammation: A comparison of rhBMP-7 and rhBMP-2. J Orthop Res 30: 1985-1994, 2012.

14. Weiskirchen R and Meurer SK: BMP-7 counteracting TGF-beta1 activities in organ fibrosis. Front Biosci (Landmark Ed) 18: 1407-1434, 2013

15. Black CR, Goriainov V, Gibbs D, Kanczler J, Tare RS and Oreffo RO: Bone Tissue Engineering. Curr Mol Biol Rep 1: 132-140, 2015.

16. Gong T, Xie J, Liao J, Zhang T, Lin S and Lin Y: Nanomaterials and bone regeneration. Bone Res 3: 15029, 2015.
17. Liu C, Abedian R, Meister R, Haasper C, Hurschler C, Krettek C, von Lewinski $\mathrm{G}$ and Jagodzinski M: Influence of perfusion and compression on the proliferation and differentiation of bone mesenchymal stromal cells seeded on polyurethane scaffolds. Biomaterials 33: 1052-1064, 2012.

18. Verdonk P, Beaufils P, Bellemans J, Djian P, Heinrichs EL, Huysse W, Laprell H, Siebold R and Verdonk R; Actifit Study Group: Successful treatment of painful irreparable partial meniscal defects with a polyurethane scaffold: Two-year safety and clinical outcomes. Am J Sports Med 40: 844-853, 2012.

19. Hannink G, de Mulder EL, van Tienen TG and Buma P: Effect of load on the repair of osteochondral defects using a porous polymer scaffold. J Biomed Mater Res B Appl Biomater 100: 2082-2089, 2012

20. Steinert AF, Rackwitz L, Gilbert F, Noth U and Tuan RS: Concise review: the clinical application of mesenchymal stem cells for musculoskeletal regeneration: current status and perspectives. Stem Cells Transl Med 1: 237-247, 2012.

21. Jagodzinski M, Drescher M, Zeichen J, Hankemeier S, Krettek C, Bosch U and van Griensven M: Effects of cyclic longitudinal mechanical strain and dexamethasone on osteogenic differentiation of human bone marrow stromal cells. Eur Cell Mater 7: 35-41; Discussion 41, 2004

22. van Tienen TG, Heijkants RG, Buma P, de Groot JH, Pennings AJ and Veth RP: Tissue ingrowth and degradation of two biodegradable porous polymers with different porosities and pore sizes. Biomaterials 23: 1731-1738, 2002.

23. Jagodzinski M, Breitbart A, Wehmeier M, Hesse E, Haasper C, Krettek C, Zeichen J and Hankemeier S: Influence of perfusion and cyclic compression on proliferation and differentiation of bone marrow stromal cells in 3-dimensional culture. J Biomech 41: 1885-1891, 2008.

24. Livak KJ and Schmittgen TD: Analysis of relative gene expression data using real-time quantitative PCR and the 2(-Delta Delta C(T)) Method. Methods 25: 402-408, 2001

25. Liu J, Zhang B, Song S, Ma M, Si S, Wang Y, Xu B, Feng K, Wu J and Guo Y: Bovine collagen peptides compounds promote the proliferation and differentiation of MC3T3-E1 pre-osteoblasts. PloS One 9: e99920, 2014.

26. Kelly DJ, Crawford A, Dickinson SC, Sims TJ, Mundy J, Hollander AP, Prendergast PJ and Hatton PV: Biochemical markers of the mechanical quality of engineered hyaline cartilage. J Mater Sci Mater Med 18: 273-281, 2007.

27. Skerry TM: The response of bone to mechanical loading and disuse: fundamental principles and influences on osteoblast/osteocyte homeostasis. Arch Biochem Biophys 473: 117-123, 2008.

28. Turner $\mathrm{CH}$, Owan I, Alvey T, Hulman J and Hock JM: Recruitment and proliferative responses of osteoblasts after mechanical loading in vivo determined using sustained-release bromodeoxyuridine. Bone 22: 463-469, 1998.

29. Jones LC, Yeoumans B, Hungerford DS and Frondoza CG: The response of osteoblast-like cells to dexamethasone and cyclic loading. Biomed Sci Instrum 42: 273-277, 2006.

30. Makhdom AM and Hamdy RC: The role of growth factors on acceleration of bone regeneration during distraction osteogenesis. Tissue Eng Part B Rev 19: 442-453, 2013.

31. Huang C, Dai J and Zhang XA: Environmental physical cues determine the lineage specification of mesenchymal stem cells. Biochim Biophys Acta 1850: 1261-1266, 2015.

32. Michalopoulos E, Knight RL, Korossis S, Kearney JN, Fisher J and Ingham E: Development of methods for studying the differentiation of human mesenchymal stem cells under cyclic compressive strain. Tissue Eng Part C Methods 18: 252-262, 2012.

33. Delaine-Smith RM and Reilly GC: Mesenchymal stem cell responses to mechanical stimuli. Muscles Ligaments Tendons J 2: 169-180, 2012

34. Murphy CM, Haugh MG and O'Brien FJ: The effect of mean pore size on cell attachment, proliferation and migration in collagen-glycosaminoglycan scaffolds for bone tissue engineering. Biomaterials 31: 461-466, 2010.

35. Karageorgiou V and Kaplan D: Porosity of 3D biomaterial scaffolds and osteogenesis. Biomaterials 26: 5474-5491, 2005 .

36. Roosa SM, Kemppainen JM, Moffitt EN, Krebsbach PH and Hollister SJ: The pore size of polycaprolactone scaffolds has limited influence on bone regeneration in an in vivo model. J Biomed Mater Res A 92: 359-368, 2010 
37. Kuboki Y, Jin Q and Takita H: Geometry of carriers controlling phenotypic expression in BMP-induced osteogenesis and chondrogenesis. J Bone Joint Surg Am 83-A (Suppl 1): S105-S115, 2001.

38. Gorna K and Gogolewski S: Biodegradable porous polyurethane scaffolds for tissue repair and regeneration. J Biomed Mater Res A 79: 128-138, 2006.

39. Gaspar DA, Gomide V and Monteiro FJ: The role of perfusion bioreactors in bone tissue engineering. Biomatter 2: 167-175, 2012.

40. Shea CM, Edgar CM, Einhorn TA and Gerstenfeld LC: BMP treatment of C3H10T1/2 mesenchymal stem cells induces both chondrogenesis and osteogenesis. J Cell Biochem 90: 1112-1127, 2003.

41. Cheng SL, Yang JW, Rifas L, Zhang SF and Avioli LV: Differentiation of human bone marrow osteogenic stromal cells in vitro: Induction of the osteoblast phenotype by dexamethasone. Endocrinology 134: 277-286, 1994.

42. Pelaez D, Huang CY and Cheung HS: Cyclic compression maintains viability and induces chondrogenesis of human mesenchymal stem cells in fibrin gel scaffolds. Stem Cells Dev 18: 93-102, 2009.

43. Mathews S, Bhonde R, Gupta PK and Totey S: Novel biomimetic tripolymer scaffolds consisting of chitosan, collagen type 1 and hyaluronic acid for bone marrow-derived human mesenchymal stem cells-based bone tissue engineering. J Biomed Mater Res B Appl Biomater 102: 1825-1834, 2014.

44. Kim K, Dean D, Mikos AG and Fisher JP: Effect of initial cell seeding density on early osteogenic signal expression of rat bone marrow stromal cells cultured on cross-linked poly(propylene fumarate) disks. Biomacromolecules 10: 1810-1817, 2009.
45. Frank O, Heim M, Jakob M, Barbero A, Schäfer D, Bendik I, Dick W, Heberer M and Martin I: Real-time quantitative RT-PCR analysis of human bone marrow stromal cells during osteogenic differentiation in vitro. J Cell Biochem 85: 737-746, 2002.

46. Xiao G, Wang D, Benson MD, Karsenty G and Franceschi RT: Role of the alpha2-integrin in osteoblast-specific gene expression and activation of the Osf2 transcription factor. J Biol Chem 273: 32988-32994, 1998.

47. Fiorentini E, Granchi D, Leonardi E, Baldini N and Ciapetti G: Effects of osteogenic differentiation inducers on in vitro expanded adult mesenchymal stromal cells. Int J Artif Organs 34 998-1011, 2011

48. Ito S, Suzuki N, Kato S, Takahashi T and Takagi M: Glucocorticoids induce the differentiation of a mesenchymal progenitor cell line, ROB-C26 into adipocytes and osteoblasts, but fail to induce terminal osteoblast differentiation. Bone 40: 84-92, 2007.

49. Kim HJ, Kim UJ, Vunjak-Novakovic G, Min BH and Kaplan DL: Influence of macroporous protein scaffolds on bone tissue engineering from bone marrow stem cells. Biomaterials 26: 4442-4452, 2005.

50. Dahlin RL, Gershovich JG, Kasper FK and Mikos AG: Flow perfusion co-culture of human mesenchymal stem cells and endothelial cells on biodegradable polymer scaffolds. Ann Biomed Eng 42: 1381-1390, 2014.

51. Kim $\mathrm{J}$ and Ma T: Bioreactor strategy in bone tissue engineering: Pre-culture and osteogenic differentiation under two flow configurations. Tissue Eng Part A 18: 2354-2364, 2012.

52. Duty AO, Oest ME and Guldberg RE: Cyclic mechanical compression increases mineralization of cell-seeded polymer scaffolds in vivo. J Biomech Eng 129: 531-539, 2007. 